\title{
SOCIALIZAÇÃO ORGANIZACIONAL NA PERSPECTIVA DE MULHERES DA POLÍCIA MILITAR
}

ORGANIZATIONAL SOCIALIZATION IN THE PERSPECTIVE OF MILITARY POLICEWOMEN

Recebido em 06.11.2018. Aprovado em 12.06.2019

Avaliado pelo sistema double blind review

\section{Glicielle Bezerra de Queiroz}

DOI: $\underline{\text { https://doi.org/10.12712/rpca.v13i2.27244 }}$

glicielle.bq@gmail.com

Programa de Pós-graduação em Avaliação de Políticas Públicas/Universidade Federal do Ceará -

Fortaleza/Ceará, Brasil

ORCID: https://orcid.org/0000-0001-9825-9464

\section{Luis Eduardo Brandão Paiva}

edubrandas@gmail.com

Programa de Pós-graduação em Administração e Controladoria/Universidade Federal do Ceará - Fortaleza/Ceará, Brasil

ORCID: https://orcid.org/0000-0002-5036-6823

\section{Tereza Cristina Batista de Lima}

\section{tcblima@,uol.com.br}

Programa de Pós-graduação em Administração e Controladoria/Universidade Federal do Ceará - Fortaleza/Ceará, Brasil

ORCID: https://orcid.org/0000-0002-6594-4921

\section{Resumo}

Esta pesquisa objetivou investigar como ocorre o processo de socialização organizacional das mulheres na Polícia Militar, baseando-se na metodologia de Taormina (1997). Realizaram-se entrevistas com oito policiais militares, podendo-se constatar que: no domínio treinamento, as habilidades de trabalho são adquiridas no curso de formação e na informalidade; no domínio da compreensão, as policiais se mostraram informadas sobre a organização; o suporte de colegas de trabalho revelou-se influente à socialização; e as perspectivas futuras convergiram à ascensão na carreira, apesar das indicações de discriminação e frustração. Os resultados contribuem para o campo dos estudos da socialização organizacional e das organizações policiais.

Palavras-chave: Gênero. Socialização Organizacional. Mulheres Policiais.

\begin{abstract}
This research aimed to investigate how the process of organizational socialization of women in the Military Police occurs, based on the Taormina (1997) methodology. Interviews were conducted with eight military police officers, and it can be seen that: in the training domain, work skills are acquired in the course of training and informality; in the field of understanding, the police officers were informed about the organization; the support of co-workers proved to be influential in socialization; and future prospects converged on career advancement despite indications of discrimination and frustration. The results contribute to the field of organizational socialization studies and military organizations.
\end{abstract}

Keywords: Gender. Organizational Socialization. Policewomen. 


\section{Introdução}

Ao longo do processo de desenvolvimento humano, o indivíduo participa de diversos grupos sociais. A socialização faz com que a pessoa internalize as normas definidoras dos critérios morais e éticos, conforme os padrões da sociedade em que está inserida. Nessa constante interação com o meio, o indivíduo vai incorporando crenças e valores, construindo padrões de comportamentos próprios para interação em cada grupo. Tais valores vão se consolidando e determinando suas escolhas, dentre elas, as escolhas profissionais (BERGER; BERGER, 2008; ELLIS et al., 2017).

Este mesmo processo revela-se no contexto das organizações. Ao ingressarem em um novo grupo, os funcionários precisam ser apresentados aos valores, tradições, normas e costumes da organização, passando por um processo de socialização, que lhes permitirá, segundo Taormina (2008), articular-se como os processos de comunicação e de integração que permeiam o fazer coletivo.

A socialização de novos membros é decisiva para a manutenção da realidade da organização. É por meio das estratégias de integração do indivíduo que os valores e comportamentos vão sendo transmitidos pela organização e apreendidos pelos novos membros (BAUER et al., 2007; ELLIS; BAUER, 2017; ELLIS et al., 2017; PERROT et al., 2014). Além disso, Borges e Albuquerque (2004) apontam que inúmeras pesquisas têm sido realizadas por psicólogos em todo o mundo acerca do tema socialização nas organizações, entretanto, no Brasil, são raras as publicações e pesquisas sobre o assunto, principalmente, tratando-se de mulheres no contexto organizacional.

Há algumas décadas, principalmente até o final do século XIX, o mercado de trabalho era um espaço de hegemonia masculina. Restritas ao ambiente familiar e tendo sua imagem frequentemente associada ao lar, as mulheres encontraram inúmeros obstáculos naturais e simbólicos, que dificultavam sua inserção no mercado de trabalho, dado que a sociedade adotava uma postura rígida e preconceituosa a respeito das atividades atribuídas à mulher (APARÍCIO et al., 2009).

Contudo, a trajetória da mulher no contexto organizacional, social e familiar vem passando por importantes modificações na sociedade contemporânea. A força de trabalho feminina tem se ampliado dentro e fora das organizações, visto que valores femininos, como cooperação e trabalho em equipe, passaram a ser apreciados em detrimento de posturas autoritárias e individualistas (QUEIROZ et al., 2010).

A inserção de mulheres em profissões tradicionalmente ocupadas por homens tem se ampliado desde o século XX. As polícias representam bem este cenário, pois mesmo envolvendo atividades profissionais consideradas masculinas, acompanharam esse fenômeno social, passando a incluir mulheres em seus quadros. Entretanto, apesar da abertura dessas instituições às mulheres, características de gênero são constantemente marcadas nas atividades, segregando os trabalhos supostamente adequados a elas, das ocupações destinadas aos homens (ANDERSON; 2014; BRASIL; PEREIRA; MACHADO, 2009; MUNDIM; TEODÓSIO, 2011; ROSA, 2012).

Nessa perspectiva, surge o seguinte questionamento: como ocorre o processo de socialização organizacional das mulheres da Polícia Militar do Ceará (PMCE)? A fim de responder a esse questionamento, definiu-se como objetivo geral para esta pesquisa: investigar como ocorre o processo de socialização organizacional das policiais da Polícia Militar do Ceará, na perspectiva das próprias profissionais.

Para tanto, apresentam-se os seguintes objetivos específicos: (i) analisar a contribuição do treinamento para que as mulheres adquiram as habilidades necessárias ao trabalho da PMCE; (ii) discutir a compreensão que as mulheres possuem sobre os aspectos organizacionais da PMCE; (iii) entender a influência do suporte de colegas de trabalho no processo de socialização organizacional das policiais 
femininas na PMCE; e (iv) identificar as perspectivas que as mulheres policiais possuem sobre seu futuro profissional na PMCE.

A investigação se deu por meio de pesquisa qualitativa, descritiva, com base em um roteiro de entrevistas alinhado aos objetivos específicos do estudo, baseando-se no modelo de socialização organizacional, proposto por Taormina (1997), descrito em quatro domínios: treinamento, compreensão, suporte de colegas de trabalho e perspectivas futuras. A coleta de dados ocorreu mediante a realização de entrevistas semiestruturadas com oito mulheres policiais da Polícia Militar do Ceará que exercem funções administrativas e/ou operacionais.

Ao longo desta pesquisa, é possível perceber como a organização foi influenciada pelo ambiente externo, principalmente por instituições similares, a reconhecer a importância das mulheres em suas corporações. Esse reconhecimento é consequência da modificação de seu posicionamento estratégico de polícia enérgica para comunitária, de caráter preventivo e educativo.

\section{Socialização Organizacional}

O tema socialização organizacional encaixa-se nos estudos da Psicologia Organizacional e do Trabalho, constituindo uma vertente cuja origem está na socialização pregada pela Psicologia Social (BORGES; ALBUQUERQUE, 2004). A socialização organizacional é frequentemente identificada como o processo principal pelo qual as pessoas se adaptam a novos empregos e funções organizacionais, tratando do conteúdo de aprendizagem e da adaptação de um indivíduo a um papel específico dentro da organização (BAUER et al., 2007; CARVALHO; BORGES; VIKAN, 2012; CHAO et al., 1994). A adaptação ao contexto do trabalho também está presente em Risk (2010), que afirma que a socialização organizacional é o período em que o indivíduo interage com o ambiente organizacional, compreendendo o contexto social em que está inserido e respondendo, positivamente ou não, resultando em um processo de adaptação ou rejeição. A socialização é também uma forma de reforçar e manter viva a cultura organizacional (SILVA; FOSSÁ, 2013).

Feldman (1976) expõe o chamado modelo dos três estágios de admissão, que apresenta três fases, a saber: antecipatória, acomodação e gerenciamento de papéis.

$\mathrm{Na}$ socialização antecipatória, há duas variáveis que mostram os avanços por meio da socialização: o realismo e a congruência. O realismo revela a coerência entre as expectativas do empregado e a imagem da organização. A congruência mensura a compatibilidade entre as competências dos funcionários e as necessidades da organização (FELDMAN, 1976).

A acomodação é a segunda etapa do processo de socialização, que se caracteriza pelo momento em que o indivíduo vê como a organização realmente é e busca se tornar um membro dela. Existem quatro formas de progredir no processo de socialização: aprendendo novas tarefas, estabelecendo novas relações interpessoais com colegas de trabalho, esclarecendo seus papéis na organização e avaliando seu progresso na organização (FELDMAN, 1976).

Para Feldman (1976), na terceira fase de socialização, denominada gerenciamento de papéis, os funcionários precisam mediar conflitos em seu trabalho com o grupo ao qual pertencem e de outros grupos com os quais se relacionam. Há, basicamente, dois tipos de conflito que precisam ser contornados: conflitos entre a vida profissional e a familiar e os conflitos nos grupos de trabalho.

Chao et al. (1994) propuseram um modelo com o objetivo de mensurar o grau de socialização em uma organização. Esses autores realizaram um levantamento da literatura e a conceituaram por meio de seis dimensões da socialização organizacional: proficiência de desempenho, relacionamento com pessoas, política organizacional, domínio da linguagem, incorporação dos objetivos e valores organizacionais e conhecimento histórico da organização. 
Van Maanen (1996) destaca que as estratégias de socialização tendem a estruturar as experiências de aprendizagem dos indivíduos, aumentando as chances de obtenção dos resultados esperados. Acrescenta, ainda, que certas estratégias tendem a estimular nos indivíduos comportamentos mais conformistas (o indivíduo se ajusta ao novo papel sem questioná-lo ou sem provocar nele mudanças significativas), enquanto outras tendem a favorecer comportamentos inovadores (o indivíduo altera o modo como o papel é tradicionalmente desempenhado na organização).

Modelos anteriores como os propostos por Feldman (1976) e Van Maanen (1996), por exemplo, descreviam o processo de socialização constituindo-o de etapas sequenciais. De acordo com Taormina (1997), a falácia de ver a socialização ocorrendo em fases tem dificultado o desenvolvimento de modelos teóricos acerca do tema. Taormina (1997) constatou, ainda, que as dimensões teóricas da socialização organizacional, bem como a maioria das variáveis pesquisadas se agrupava em algumas poucas e amplas categorias, denominadas "domínios", uma vez que são partes do processo contínuo em que acontece a socialização organizacional e podem ajudar a sintetizar as variáveis que estão sendo investigadas. Desta forma, os quatro domínios são: treinamento, compreensão, suporte de colegas de trabalho e perspectivas futuras.

O primeiro domínio, treinamento, é definido como o ato, processo ou método pelo qual se adquire qualquer tipo de habilidade funcional ou capacidades necessárias à realização de um trabalho específico (TAORMINA, 1997). Portanto, está ligado às habilidades relacionadas ao trabalho. O treinamento pode ser formal, que envolve qualquer tipo de programa de instrução estruturado pela organização que favoreça o aprimoramento das habilidades de trabalho; ou informal, que engloba qualquer forma não estruturada pela qual um trabalhador aprimora suas habilidades no local de trabalho, podendo ocorrer de diversas formas, como por tentativa e erro, observação ou pedindo ajuda aos colegas a respeito de algum trabalho específico (TAORMINA, 1997).

O domínio da compreensão está relacionado com a cognição do indivíduo. Taormina (1997) o define como a capacidade de aplicar conceitos para explicar algo. A compreensão constitui um domínio do processo de socialização organizacional, pois é necessária em todos os aspectos relacionados ao trabalho.

Taormina (1997) conceitua o domínio suporte de colegas de trabalho como o sustento emocional, moral ou instrumental que é fornecido sem compensação financeira por outros funcionários da organização em que se trabalha com o objetivo de aliviar ansiedade, medo ou dúvida. Este suporte pode ser oferecido por diversos agentes atuantes na organização, sobretudo pelos pares. Pode referir-se a incentivos verbais, consolos comportamentais e até auxílios materiais, tal como o empréstimo de equipamentos.

O domínio das perspectivas futuras se refere à visão que o empregado tem do quanto sua carreira será bem-sucedida dentro da organização. Os aspectos capazes de tornar a organização atrativa ao funcionário podem ser: estabilidade, remuneração satisfatória, promoções, benefícios, reconhecimento, dentre outros. Este domínio pode ser considerado uma forma de socialização organizacional, pois faz parte de um sistema que os funcionários devem aceitar para se ajustarem à organização (TAORMINA, 1997).

\section{Mulheres Policiais no Mercado de Trabalho}

No Brasil, no início do século XIX, o trabalho feminino se concentrava nas fábricas têxteis já que as mulheres eram uma mão de obra barata e qualificada, além do fato de o trabalho nas confecções ser considerado compatível com as habilidades femininas desenvolvidas dentro do lar (MOURA, 1989).

O movimento feminista propôs uma discussão acerca do papel da mulher no seio da sociedade, das relações familiares, das leis trabalhistas, das responsabilidades sexuais e reprodutivas, das políticas públicas e, principalmente, das relações interpessoais, dando origem a uma nova identidade feminina a partir da noção de gênero, com a reinvindicação dos direitos da mulher (SILVA, 2010). 
Alguns dos obstáculos e preconceitos impostos à mulher no passado continuam presentes nos dias de hoje, porém tiveram alterações importantes no que se refere às mulheres nas organizações. Elas têm conquistado mais espaço nas organizações, disputando, inclusive, cargos de poder com os homens.

Grande parte das organizações foi criada por homens e para homens, dessa forma, ideais de competência e liderança têm como base estereótipos masculinos de resistência, agressividade e objetividade (FERNANDO, 2012; MEYERSON; FLETCHER, 2000). Sendo assim, ao se inserir em uma organização, cabe à mulher reafirmar sua identidade feminina, refutando qualquer referência predominantemente masculina (SOUZA; CORVINO; LOPES, 2013). Para Kanan (2010), no Brasil, a presença de mulheres nos mais diversos espaços se justificam por três aspectos: o declínio da taxa de fecundidade; o aumento do nível de instrução da população feminina; e a ascensão do número de lares sustentados por mulheres.

As mulheres executivas são as que mais sofrem com a cobrança e sobrecarga de trabalho, principalmente, as que são casadas e têm filhos. Muitas empresas invadem a privacidade familiar exigindo que seus funcionários estejam sempre conectados, tornando-os ausentes mesmo quando estão em seus lares. Essa prática afeta negativamente a rotina atarefada das mulheres que trabalham fora, já que prejudica o pouco tempo disponível para se dedicar à família (CARVALHO NETO; TANURE; ANDRADE, 2010).

As mulheres ainda experimentam sentimentos dúbios quando o assunto se refere a suas experiências profissionais, uma vez que, por um lado, ficam satisfeitas com o sucesso alcançado, mesmo diante das dificuldades, por outro, anseiam por serem aceitas, valorizadas e respeitadas (SILVEIRA, 2009).

\section{Trajetória das mulheres na Polícia Militar}

Segundo Musumeci e Soares (2012), na década de 1980, o Brasil passou por importantes avanços no que diz respeito às questões de gênero dentro da segurança pública. Com a criação de delegacias, na Polícia Civil, destinadas ao atendimento de mulheres vítimas de violência doméstica, as policiais tiveram a oportunidade de ocupar espaços no interior dessas organizações.

Para Cappelle e Melo (2010), a Polícia Militar é como uma espécie de "gueto masculino" no qual os estereótipos da representação social do que significa "ser homem" e "ser mulher" estão incrustados por todos os lados. Essa distinção é acentuada pela cultura das organizações militares brasileiras que, além da hierarquia e da disciplina, remontam a valores patriarcais resultantes de um processo histórico de subordinação de gênero (CAPPELLE et al., 2002).

Estudos atuais envolvendo poder e gênero no alto comando administrativo da Polícia Militar de Minas Gerais revelaram que as policiais sentem a constante necessidade de autoafirmação pois, segundo elas, para serem reconhecidas no mesmo nível de um colega homem, precisam se sobressair em suas funções (RIBEIRO; GARCIA, 2015). Os autores destacam ainda que, embora haja uma tentativa de fazer valer o "Mito da Igualdade", a segregação de gênero pode ser percebida, mesmo que de forma velada.

Ainda que não haja restrições oficiais à ascensão feminina na carreira policial, há uma segregação entre homens e mulheres (DONADIO, 2009). As mulheres exercem tarefas administrativas, enquanto eles trabalham com o policiamento ostensivo. Os estudos de Cappelle e Melo (2010) revelaram que há certa discriminação dentro da corporação, já que as policiais somente são aceitas se exercerem funções tipicamente femininas. Ainda segundo as autoras, as policiais que se desvirtuam desse padrão são vítimas de preconceito por parte dos colegas.

Os trabalhos de Capelle e Melo (2010) e de Rosa (2012) constataram também, por meio de relatos, que o assédio moral e sexual se faz presente no cotidiano das policiais militares, e são manifestados por meio de piadas que desqualificam o trabalho feminino, além de investidas desrespeitosas por parte dos colegas. Esses tipos de perseguição raramente são denunciados, pois muitas policiais receiam sofrer represálias. 
Em resumo, na trajetória das mulheres na Polícia Militar, destacam-se alguns avanços pela sua inserção na corporação, mas ainda é possível encontrar situações de discriminação e assédio por parte dos colegas.

\section{Procedimentos metodológicos}

Esta pesquisa apresenta natureza qualitativa de caráter descritivo, cujo universo é composto por mulheres que trabalham na Polícia Militar do Ceará (PMCE). O policiamento feminino na PMCE surgiu com a criação da Companhia da Polícia Militar Feminina por meio dos artigos 154 e 155 da Constituição Estadual e pela Lei no 11.035, de 23 de maio de 1985, tendo sua implantação ocorrido somente em 1994, com a publicação do edital para concurso público no $011 / 1994$, da Diretoria de Ensino da Corporação, para recrutamento, seleção, matrícula e admissão de mulheres (MUSEU DA PMCE, 2015).

Foram obtidas entrevistas com oito mulheres policiais que realizam trabalhos administrativos e/ou operacionais na PMCE. As participantes são identificadas pelo termo "Entrevistada" - código "E", seguido pela numeração correspondente variando de 1 (um) a 8 (oito). Foram selecionadas por conveniência, de maneira aleatória, segundo a disponibilidade das policiais, de acordo com a permissão concedida pelos superiores das unidades da PMCE nas quais o estudo foi realizado.

Para a coleta de dados, utilizou-se o método das entrevistas individuais, semiestruturadas, conduzidas com base em um roteiro cujas perguntas estão ancoradas no referencial teórico e alinhadas com os objetivos deste estudo.

O roteiro utilizado foi dividido em dois grupos: o primeiro relativo aos dados sociodemográficos; e o segundo relacionado ao modelo de socialização organizacional de Taormina (1997), descrito em quatro domínios: treinamento, compreensão, suporte de colegas de trabalho e perspectivas futuras. Esses domínios estão segmentados nos objetivos específicos desta pesquisa (QUADRO 1).

Quadro 1. Grupos de perguntas da pesquisa

\begin{tabular}{|c|c|l|}
\hline $\begin{array}{c}\text { Grupo de } \\
\text { Perguntas }\end{array}$ & $\begin{array}{c}\text { Objetivos } \\
\text { Específicos }\end{array}$ & \multicolumn{1}{c|}{ Objetivo do Grupo de Perguntas } \\
\hline $1^{\circ}$ & - & Obter dados sociodemográficos das entrevistadas \\
\hline \multirow{4}{*}{$2^{\circ}$} & Treinamento & Conseguir informações sobre o treinamento das entrevistadas \\
\cline { 2 - 3 } & \begin{tabular}{c} 
Compreensão \\
\cline { 2 - 3 }
\end{tabular} & $\begin{array}{l}\text { Obter informações sobre a compreensão dos aspectos organizacionais pelas } \\
\text { entrevistadas }\end{array}$ \\
\cline { 2 - 3 } & Pe trabalho & $\begin{array}{l}\text { Conseguir informações sobre o suporte que as entrevistadas recebem dos colegas } \\
\text { de trabalho }\end{array}$ \\
\hline
\end{tabular}

Fonte: Elaborado pelos autores.

Antes da realização da coleta de dados, foram prestados esclarecimentos sobre os objetivos da pesquisa e esclarecidas as dúvidas das participantes a respeito da entrevista, bem como dos procedimentos metodológicos utilizados para a obtenção dos resultados.

Para o tratamento dos dados da pesquisa, adotou-se o método da análise de conteúdo por ser uma forma de converter um texto em variáveis numéricas para as análises das entrevistas (BARDIN, 1977). Nesse método, o material analisado é agrupado em várias unidades de código definidas pelo pesquisador, criando-se uma moldura de codificação na qual as unidades são listadas verticalmente, permitindo a análise de cada comunicação a ser acrescentada no eixo horizontal (COLLIS; HUSSEY, 2005).

Para cada uma das categorias de análise, foram estabelecidas duas unidades de contexto e algumas unidades de registro, a fim de facilitar a identificação dos elementos nas entrevistas. 
Quadro 2. Categorias de análise, unidades de contexto e unidades de registro

\begin{tabular}{|c|c|c|}
\hline $\begin{array}{l}\text { CATEGORIA } \\
\text { DE ANÁLISE }\end{array}$ & $\begin{array}{c}\text { UNIDADES } \\
\text { DE CONTEXTO }\end{array}$ & $\begin{array}{l}\text { UNIDADES } \\
\text { DE REGISTRO }\end{array}$ \\
\hline \multirow{4}{*}{ Treinamento } & \multirow{2}{*}{ Treinamento Formal } & Curso de formação \\
\hline & & Cursos oferecidos pela organização \\
\hline & \multirow{2}{*}{ Treinamento Informal } & Aprendizado diário \\
\hline & & Auxílio dos colegas \\
\hline \multirow{4}{*}{ Compreensão } & Conhecimento prévio da organização & Informações fornecidas por amigos e familiares \\
\hline & \multirow{3}{*}{ Conhecimento atual da organização } & $\begin{array}{l}\text { Reconhecimento da importância da missão da } \\
\text { organização }\end{array}$ \\
\hline & & $\begin{array}{l}\text { Identificação e influência dos valores organizacionais } \\
\text { no âmbito profissional e privado }\end{array}$ \\
\hline & & $\begin{array}{l}\text { Familiaridade com os costumes, com a história e com } \\
\text { as tradições da organização }\end{array}$ \\
\hline \multirow{5}{*}{$\begin{array}{l}\text { Suporte de colegas } \\
\text { de trabalho }\end{array}$} & \multirow{4}{*}{ Apoio dos colegas de trabalho } & Apoio nas questões pessoais e profissionais \\
\hline & & Companheirismo \\
\hline & & Amizade \\
\hline & & Minimização do estresse \\
\hline & Falta de apoio dos colegas de trabalho & Preconceito contra a mulher \\
\hline \multirow{4}{*}{$\begin{array}{l}\text { Perspectivas } \\
\text { futuras }\end{array}$} & \multirow{2}{*}{ Expectativas para o futuro } & Ascensão na carreira \\
\hline & & Promoção \\
\hline & \multirow{2}{*}{ Frustrações } & Demora das promoções \\
\hline & & Desmotivação \\
\hline
\end{tabular}

Fonte: Elaborado pelos autores.

\section{Apresentação e análise dos resultados}

\section{Perfil das entrevistadas}

Com base nas oito entrevistas que foram realizadas com as policiais militares, destaca-se o perfil da amostra, a seguir:

Quadro 3. Perfil das entrevistadas

\begin{tabular}{|c|c|c|c|c|c|}
\hline Código & $\begin{array}{c}\text { Faixa etária } \\
\text { (anos) }\end{array}$ & Escolaridade & $\begin{array}{c}\text { Estado } \\
\text { civil }\end{array}$ & $\begin{array}{c}\text { Tempo na } \\
\text { organização }\end{array}$ & $\begin{array}{c}\text { Função na } \\
\text { organização }\end{array}$ \\
\hline E1 & 29 a 33 & Superior Completo & Casada & 8 anos & Cabo \\
\hline E2 & 29 a 33 & Pós-graduação Completa & Casada & 6 anos & Soldado \\
\hline E3 & 19 a 23 & Superior Incompleto & Solteira & 1 ano e 7 meses & Soldado \\
\hline E4 & 39 a 43 & Pós-graduação Completa & Casada & 21 anos & Ten. Coronel \\
\hline E5 & 39 a 43 & Pós-graduação Completa & Casada & 21 anos & Sargento \\
\hline E6 & 39 a 43 & Pós-graduação Incompleta & Divorciada & 21 anos & Sargento \\
\hline E7 & 19 a 23 & Superior Incompleto & Casada & 1 ano e 7 meses & Soldado \\
\hline E8 & 29 a 33 & Superior Completo & Casada & 5 anos & Soldado \\
\hline
\end{tabular}

Fonte: Dados da pesquisa.

Analisando os dados do Quadro 3, observou-se uma concentração nas faixas etárias de 29 a 33 anos e de 39 a 43 anos. O nível de escolaridade predominante foi pós-graduação completa; o estado civil dominante foi de mulheres casadas. Ademais, a renda familiar mais comum foi superior a $\mathrm{R} \$ 4.728,01$, excetuandose apenas dois sujeitos com remuneração inferior. $O$ tempo médio na organização foi de aproximadamente 10 anos e oito meses. 
A próxima subseção apresenta a análise dos dados obtidos na aplicação da segunda parte do roteiro de entrevistas.

\section{Processo de socialização organizacional}

\section{Treinamento}

Os resultados foram indicados pelas unidades de contexto: treinamento formal e treinamento informal. Para a primeira, os resultados expressaram-se por meio das unidades de registro "curso de formação" e "cursos oferecidos pela organização". Enquanto na segunda, destacam-se as unidades de registro: "aprendizado diário" e "auxílio dos colegas".

De acordo com as transcrições das entrevistas, foram identificadas 91 citações relacionadas com o domínio treinamento. O treinamento formal foi mencionado em 62 oportunidades (68\%), em contrapartida, houve 29 menções $(32 \%)$ ao treinamento informal.

Segundo Taormina (1997), o domínio treinamento corresponde à aquisição de habilidades funcionais e é oferecido pela organização com o objetivo de socializar o novo funcionário. As entrevistadas declararam que existe um curso de formação, com duração de seis meses, ofertado no início da carreira, que aborda aspectos teóricos e práticos de uma forma geral. Nele, as policiais recém-ingressas, vindas do mundo civil, são estimuladas a desenvolver habilidades básicas necessárias, socializando-se com o trabalho na polícia:

\footnotetext{
"Quando a gente faz o treinamento, a gente passa por uma disciplina que se chama Técnicas Policiais Militares, dentro dessa disciplina a gente aprende as técnicas de abordagem, a gente tem também aulas de direito, a gente tem aula de gerenciamento de conflitos, como gerenciar conflitos na rua, a gente teve aula de manuseio de armamentos e equipamentos, isso inclui algemas, tonfa, armamento letal, armamentos não-letais, como gás” (E8).
}

Após o curso de formação, primeiro treinamento da carreira de um policial, os relatos revelam que não existe um programa de capacitação contínuo, já que é difícil afastar as policiais de seu trabalho para que esta ação seja realizada, como exposto no trecho:

\footnotetext{
“(...) a instituição ainda tem um déficit de efetivo, então a gente entende que é difícil também está disponibilizando policiais, tirando mesmo das ruas para proporcionar cursos porque vai ter que baixar viatura e existe uma carência em cada área de uma viatura (...). E se você tira dez policiais, por exemplo, para estar se reciclando, para estar aprendendo novas técnicas, aquilo ali vai causar um déficit para a comunidade, então é complicado (...) os comandantes têm um interesse, mas ao mesmo tempo é difícil. Como disponibilizar essas pessoas se não tem outras para substituí-las? (...)" (E1).
}

Apesar de não existir um programa de capacitação permanente, as policiais revelaram que, ao passar por treinamentos, se sentem mais confiantes e seguras para realizar seu trabalho. Sem um programa de treinamento contínuo, precisam buscar desenvolver suas habilidades por meio de cursos, não obrigatórios, ofertados por outras instituições ligadas ao Estado. Grande parte das entrevistadas revelou que sempre se dispõe a fazê-los para obter conhecimentos que possam ajudá-las em seu dia a dia de trabalho.

Além do treinamento formal, como é o caso do curso de formação, o treinamento informal pode complementar o processo de aquisição do conhecimento relacionado ao trabalho, conforme exposto por Taormina (1997). Van Maanen (1996) também versa sobre o assunto afirmando que os processos formais de socialização são apenas a primeira parte da socialização, já que a segunda parte ocorre quando o funcionário é alocado em sua posição dentro da organização, devendo aprender informalmente as práticas reais de seu departamento. 
As entrevistadas relatam que o trabalho é realmente aprendido no dia a dia, praticando, nas ruas e lidando com situações reais:

\footnotetext{
"A gente faz um curso de formação, (...) ele te dá por alto o que é o serviço, mas você vai aprender mesmo no dia-a-dia, depois que você assume o cargo público, no cotidiano das ruas, nas viaturas é que você vai aprender o que é o serviço de polícia” (E2).

“(...) a rua, ela exige mais, aí o aprendizado vem com o tempo (...) é a rua que ensina, é trabalhando que a gente vai aprender (...)” (E5).
}

Apesar de reconhecerem a carência de treinamento, as policiais relataram que suas habilidades são aprendidas no dia a dia de trabalho com a ajuda dos colegas. Conforme Taormina (1997), o treinamento informal também pode ocorrer por tentativa e erro ou observação e por meio da ajuda de colegas, como descrito pelas entrevistadas na PMCE.

\section{Compreensão}

Os resultados são indicados pelas unidades de contexto: conhecimento prévio da organização e conhecimento atual da organização. Para a primeira, os resultados são expressos por meio da unidade de registro "informações fornecidas por amigos e familiares". Já para a segunda, as unidades de registro são: "reconhecimento da importância da missão da organização", "identificação e influência dos valores organizacionais no âmbito profissional e privado", "familiaridade com os costumes, com a história e com as tradições da organização".

Foram identificadas 75 citações relacionadas com o domínio Compreensão. O conhecimento prévio da organização foi mencionado em 8 oportunidades (11\%) e, em contrapartida, houve 67 menções $(89 \%)$ ao conhecimento atual da organização.

As organizações militares estão inseridas em uma realidade bastante distinta do mundo civil. Ao ingressar nesse ambiente cercado por símbolos e seus significados, o indivíduo necessita entendê-los para que, dessa forma, possa se socializar com maior facilidade. A compreensão influencia no processo de socialização mesmo antes do efetivo ingresso na organização, por meio de informações obtidas por intermédio de fontes possuidoras, ou não, de certo nível de credibilidade (TAORMINA, 1997).

Algumas entrevistadas relataram que não tinham conhecimento prévio acerca da Polícia Militar, outras já tinham amigos e/ou familiares ligados à instituição que lhes tinham fornecido algumas informações superficiais a respeito da organização. Isto pode ser verificado nos fragmentos da Entrevistada 1: “(...) eu já tinha uma noção porque eu tenho vários familiares que também fazem parte da corporação... tinha uma ideia (...)" e da Entrevistada 3: "Já conhecia, mas não tanto quanto agora. Porque eu tinha alguns parentes na polícia (...)".

Ao ingressar, o indivíduo começa a conhecer a realidade organizacional e passa por uma fase de ajustamento, identificada por Risk (2010) como choque de realidade, que pode ser observado no depoimento a seguir:

\footnotetext{
"Nunca, nunca nem sonhava o que era ser da polícia. Eu achava que era pra trabalhar interno, nunca achei que fosse a trabalhar na rua, mas aí quando eu entrei na polícia é que eu fui compreendendo realmente o que era ser polícia, que é realmente você se doar, você realmente estar disponível, 24 horas da sua vida, porque mesmo que você não esteja fardada, mas você é polícia e a população, se ela sabe disso, ela lhe cobra. Então a gente só vai compreender isso mesmo quando a gente entra na corporação" (E6).
}

Além do choque de realidade, existem outras dificuldades no processo de socialização, principalmente no que diz respeito a se adaptar à organização. Há ainda o Código Disciplinar que incide sobre as faltas, desde as mais leves, como não prestar continência (saudação militar) a um superior hierárquico, até as mais graves, como desacatar uma autoridade. Essas particularidades causam um estranhamento aos 
indivíduos advindos do mundo civil e podem tornar o processo de socialização um pouco mais complicado, como relatado pela Entrevistada 1:

\begin{abstract}
"No momento em que eu entrei, assim, foi um pouco difícil porque a gente tem hierarquia militar, tem um Código Disciplinar, então assim, você assimilar todos esses valores da instituição é um pouco difícil, a gente vem do mundo civil e ingressar no mundo militar, tem as suas diferenças então demora um pouco a sua adaptação" (E1).
\end{abstract}

Algumas entrevistadas revelaram que o seu primeiro contato com a cultura militar se deu no curso de formação, também conhecido como recrutamento, no qual as aspirantes têm disciplinas com o objetivo de familiarizá-las com a Polícia Militar.

Uma das entrevistadas revelou seu sentimento após ter passado pelo curso de formação da Polícia Militar: "Eu me senti policial. Eu entrei muito civil, eu não sabia nada do que era polícia (...). Depois que terminou o curso, pronto, aí eu sou policial" (E7). Esta afirmação corrobora com Fernandes e Zanelli (2006), que ressaltam que reconhecer os significados, além de se familiarizar com as percepções e comportamentos mais aceitos e valorizados na organização, conduz os funcionários a uma uniformidade de atitudes, o que possibilita uma maior coesão. As estratégias de socialização adotadas pela PMCE estimulam comportamentos de conformidade nos novos indivíduos. Conforme Van Maanen (1996), isso pode ser explicado pelo fato de a organização buscar reforçar e manter viva a cultura vigente, ideia corroborada por Silva e Fossá (2013).

A integração à organização também está relacionada ao domínio da compreensão, à medida que o indivíduo toma conhecimento daquilo que o cerca, entendendo melhor seu trabalho, papéis, objetivos, valores e cultura da organização. As entrevistadas foram unânimes em reconhecer a importância da polícia e consequentemente de seu trabalho.

As entrevistadas, à exceção de uma, consideraram-se integradas. Algumas relacionaram a integração à adaptação com o trabalho na polícia e ao tempo de serviço, como evidenciado pela Entrevistada 1: "Eu já faço parte há oito anos, já passei seis anos trabalhando nas ruas e agora estou trabalhando na parte administrativa... já me sinto adaptada." A Entrevistada 6 relacionou a integração a sua identificação, satisfação e ao seu envolvimento com o trabalho, e isto confirma o que foi postulado por Taormina (1997).

Outra entrevistada destacou que ainda não se sente completamente integrada, mesmo após seis anos de trabalho na organização:

"Não... ainda não, ainda em fase de integração, (...) ainda estou em processo de adaptação. É bem complicado você entrar numa instituição militarizada, predominantemente masculina e (...) eu fui expulsa e fui reintegrada novamente porque não acatava determinadas ordens, participei do movimento grevista... fui a única mulher dos quadros daquela greve que foram demitidas e retornaram agora..." (E2).

Em seu discurso, a Entrevistada 2 revelou não reconhecer a cultura militar como necessária à execução da missão da polícia o que reafirma a teoria de Taormina (1997), a qual versa sobre a compreensão da cultura vigente como fator importante no processo de socialização e integração do indivíduo:

\footnotetext{
“(...) É... para se familiarizar é um pouquinho complicado porque o regime militaresco, ele te traz certas dificuldades. (...) o militarismo, ele entrou em decadência, então ele não é mais algo que a gente possa está usando dentro da nossa instituição... eu, pessoalmente, acho que a polícia estadual ganharia muito mais valorização se deixasse de ser militarizada (...)” (E2).
}

Taormina (1997) inclui o envolvimento com o trabalho no domínio Compreensão. Algumas entrevistadas se mostraram altamente envolvidas com seu trabalho e com seu papel na instituição, tanto que revelaram exercer sua função mesmo quando não estão em serviço: 
"Quando a gente entra na polícia, a gente é policial 24 horas por dia, você não é policial só no horário que tá trabalhando, não, você é policial 24 horas, tanto é que você vê, às vezes, um caso de um policial de folga e ele se envolve em alguma coisa (...) você não deixa de ser policial, até quando morre a gente vai de farda (...) quer dizer, você entrou na polícia você vai ser dela pra sempre " (E5).

O alto grau de socialização das policiais femininas é revelado quando elas afirmam que o fato de elas serem policiais militares é capaz de influenciar seu comportamento ou ações na vida privada, corroborando com Calazans (2004), que versa a respeito da sobreposição da imagem da policial militar ao caráter pessoal da mulher:

\begin{abstract}
"Influi, Influi (no comportamento). A gente acaba se tornando mais assim, observador, mais atento, mais preocupado também(...). No seu dia-a-dia você leva isso, a questão da disciplina também, você acaba levando para outros âmbitos da sua vida” (E1).

"Com certeza, eu aprendi muito com a Polícia Militar, eu aprendi demais mesmo. Tanto é que eu estagiando num hospital, uma pessoa disse para mim que é muito bom trabalhar com militar, porque o militar só chega na hora, o militar realmente é disciplinado, ele não falta. Então a Polícia Militar ela incute isso na sua cabeça, às vezes, você nem quer ser assim, mas você é assim porque você vai aprendendo no dia a dia (...)" (E6).
\end{abstract}

Observa-se, portanto, como a compreensão da organização é importante para o processo de socialização das policiais na PMCE, visto que o regime militar tem inúmeras características incomuns desconhecidas pelas organizações civis.

\title{
Suporte dos colegas de trabalho
}

Os resultados são indicados pelas unidades de contexto: apoio dos colegas de trabalho e falta de apoio dos colegas de trabalho. Para a primeira, os resultados são expressos por meio das unidades de registro "apoio nas questões pessoais e profissionais", "companheirismo", "amizade" e "minimização do estresse". Para a segunda, a unidade de registro é "preconceito contra a mulher".

Conforme as transcrições das entrevistas, foram identificadas 70 citações (86\%) relacionadas ao apoio dos colegas de trabalho e 11 unidades (14\%) ligadas à falta de apoio, totalizando 81 citações para o domínio suporte dos colegas de trabalho.

O suporte dos colegas de trabalho se revelou bastante influente na PMCE, uma vez que as entrevistadas revelaram que este suporte está presente desde o ingresso, já que se sentiram acolhidas pela equipe de trabalho, o que facilitou o processo de socialização. Taormina (1997) ressalta que após um primeiro momento, o indivíduo identifica seus colegas mais próximos, podendo surgir relações de amizade. Foi perceptível no discurso das entrevistadas que a amizade e o companheirismo entre colegas de trabalho estão presentes na PMCE, e que esses sentimentos chegam a ultrapassar os limites da vida profissional:

"A gente passa muito tempo convivendo e você faz amigos mesmo, de conhecer as famílias, de frequentar a casa das pessoas, você cria assim um elo” (E1).

“(...) eu tenho muitos amigos aqui. A Polícia Militar ela tem isso, quando você chega, você não tem amigos, eu tenho irmãos, a gente costuma dizer que nós somos uma família, nós somos irmãos de farda realmente, independentemente de ser homem ou mulher, nós somos considerados irmãos de farda” (E6).

Ao serem perguntadas sobre o gênero dos colegas com os quais tinham maior afinidade, a maioria das entrevistadas respondeu que se relaciona bem tanto com mulheres quanto com homens. Esse sentimento de amizade sem distinção de gênero contradiz o que foi afirmado por Rosa (2012), de que o sentimento predominante entre as policiais investigadas era de afinidade para com os homens e de rivalidade com as outras mulheres. 
Todas as entrevistadas admitiram que o apoio dos colegas de trabalho é capaz diminuir situações estressantes, o que corrobora com o afirmado por Taormina (1997):

"Com certeza, numa situação de risco você ter uma equipe ali, que você confia, faz toda a
diferença" (E1).
"É, a gente quando tá trabalhando, a gente tá na rua, a gente sente tensa porque qualquer hora
pode acontecer alguma coisa, agora quando você tá perto de pessoas que você confia, aquilo ali
ameniza porque você tem mais segurança" (E5).

As entrevistadas também reconhecem a influência positiva que o suporte dos colegas de trabalho lhes oferece, contribuindo para seu bem-estar não só dentro, mas também fora da organização. Esse apoio é estendido, inclusive a questões de ordem pessoal, entendido por Taormina (1997) como um sustento emocional ou moral fornecido sem compensação financeira:

“A polícia é muito corporativista. Muito, muito nesse sentido de se tiver uma policial ou um
policial em situação de... conflito familiar ou com algum problema de ordem pessoal, eles
rapidamente já chegam junto perguntam se tá precisando de ajuda, então se você de repente
quiser se abrir, se abre e os próprios amigos aqui da unidade operacional vão te ajudando a sair
da situação de risco ou da situação que você esteja aí passando na vida particular ou até mesmo
aqui na vida profissional” (E2).
“(...) trabalhando numa equipe e um não tá bem, a equipe toda se mobiliza pra que ele melhore”
(E5).

Algumas entrevistadas com maior tempo na organização, principalmente as integrantes da primeira turma de mulheres na Polícia Militar, revelaram que, no início, o relacionamento com os colegas homens era complicado. Elas atribuem esta dificuldade ao fato de a corporação não estar, naquela época, acostumada a trabalhar com mulheres. É importante destacar que a falta de apoio dos colegas pode gerar frustrações, visto que é difícil trabalhar em um ambiente no qual não há sensibilidade:

"Existe sim preconceito contra a mulher, existe sexismo (...) a dificuldade que eu tinha era de mostrar que eu era igual aos demais, que eu deveria ser tratada igual aos demais, aos meus pares $(\ldots) "(\mathrm{E} 4)$.

"Foi muito difícil, a nossa instituição ela só tinha homem, ela não estava adaptava pra ter mulheres, a Polícia já tinha mais de cem anos quando nós entramos, então não estava adaptada pra nos receber e tinha muito assédio, tinha muita desvalorização com a gente, as pessoas não olhavam muito bem pra gente" (E6).

“(...)eu fui trabalhar num local em que eles preferiam não trabalhar com policiais femininas, eles olhavam: Não, na minha viatura, não” (E8).

Os comentários das entrevistadas revelaram a presença de sexismo (KANAN, 2010), assédio moral (MORAES, 2010), comentários machistas (IRAGARAY; VERGARA, 2009), corroborando com as ideias de Capelle et al. (2002), que comentam que a distinção acentuada entre homens e mulheres ainda está muito presente em organizações militares devido aos seus valores patriarcais.

\section{Perspectivas futuras}

Os resultados são indicados por duas unidades de contexto: expectativas para o futuro e frustrações. Para a primeira unidade de contexto, os resultados são expressos por meio das unidades de registro "ascensão na carreira", "promoção". Para a segunda, as unidades de registro são: "demora das promoções" e "desmotivação".

Nas entrevistas, foram identificadas 65 citações relacionadas com o domínio perspectivas futuras. A unidade de contexto expectativas para o futuro foi mencionada em 38 oportunidades (58\%) e, em contrapartida, houve 27 menções $(42 \%)$ às frustrações. 
Como visto anteriormente, os inúmeros aspectos que tornam o ingresso em determinada organização atrativo fazem parte do domínio das perspectivas futuras (TAORMINA, 1997). Nas entrevistas, foi possível identificar que a estabilidade foi o principal atrativo para o ingresso a entrada da maioria das entrevistadas na PMCE.

Como visto no modelo de Feldman (1976), a socialização antecipatória ocorre antes mesmo do ingresso do funcionário, que cria expectativas sobre seu futuro dentro da organização. $O$ foco na ascensão na carreira é característica marcante no discurso das entrevistadas e pode ser compreendido, além da questão salarial embutida na promoção, como um reflexo da própria cultura militar, caracterizada por sua hierarquia, representada por meio das patentes que revelam o grau de autoridade e o posto ou graduação na qual aquele indivíduo se encontra.

Taormina (1997) também afirma que a equidade é um componente do domínio das perspectivas futuras, tanto que, se um indivíduo ter uma aspiração e esta for atingida por outro, o processo de socialização é desfavorecido:

"Já fui preterida por ser mulher... teve uns cursos aqui em 2000, da SUAT americana mesmo, veio pra cá e... eu e uma amiga minha, a gente tinha um currículo maravilhoso, operacional e a gente foi preterida... a gente foi preterida mesmo porque era mulher, porque tinha tantas vagas e iam ser as vagas dos homens... do GATE, aí deram as vagas pra eles e excluíram a gente... essas coisas doeram ao longo da vida. Teve outras também: medalhas que você via que não era, necessariamente... teve alguns choros, sim" (E4).

Segundo Taormina (1997), a frustração pode ser incluída no domínio das perspectivas futuras, já que ela corresponde ao não atendimento de expectativas. No caso das policiais entrevistadas a frustração comum foi a demora nas promoções dentro da polícia:

“(...) a gente completava o tempo pra promoção e isso não acontecia (...) às vezes você dá o máximo e nem sempre você é reconhecido por isso” (E1).

“(...) quando eu entrei, que eu vi a realidade, eu passei a desacreditar. (...)a gente se sentia, muito frustrada, era salário baixo, sem ascensão de promoção, muitas dificuldades (...) (E2).

"Eu me sentia muito frustrada porque eu tinha dezoito anos de polícia e eu nunca tinha recebido uma promoção (...)" (E5).

Essas frustrações geraram sentimentos negativos em relação ao trabalho e à organização, como desânimo e desmotivação das policiais. A demora nas promoções, segundo os depoimentos, foi causada pelo não cumprimento de uma lei estadual que versa sobre as promoções na Polícia Militar do Estado do Ceará. Com a mudança de governo, ocorreram muitas promoções, o que reacendeu as expectativas não só das policiais entrevistadas como da corporação como um todo.

Em resumo, a análise dos resultados permitiu observar, em cada domínio investigado, a presença tanto de aspectos favoráveis quanto desfavoráveis, relacionados ao processo de socialização organizacional das mulheres na PMCE.

No domínio treinamento, como aspecto favorável à socialização, destaca-se, em um primeiro momento, a importância atribuída ao curso de formação que ensina as técnicas da prática policial e introduz o policial recém-ingresso na cultura militar e, em um segundo momento, o constante aprendizado informal que ocorre no dia a dia com os colegas. Como aspecto negativo, há dificuldade para deslocar grupos de policiais para realizar treinamentos, pois os serviços prestados ficariam suspensos. Outra dificuldade para o processo de socialização é que o trabalho tem características particulares que são aprendidas diariamente, na prática do policial em suas ações operacionais.

No domínio compreensão, há um reconhecimento da importância da missão da polícia e do papel do policial para a sociedade. Revela-se uma sensação de pertencimento à organização. Os valores 
organizacionais têm características marcantes, apresentando influências no âmbito profissional, bem como na vida privada. Já como aspecto desfavorável à socialização, é possível citar a rigidez da cultura militar, de forte caráter simbólico e disciplinar, como um desafio ao universo civil, em especial para as mulheres, pela predominância de aspectos "masculinizados".

No domínio suporte de colegas de trabalho, a significativa relação de companheirismo, a amizade e o apoio dos colegas favorecem a socialização e proporcionam uma minimização do estresse. Por outro lado, a desvalorização das profissionais pelo fato de serem mulheres e a necessidade de se esforçarem para receber um tratamento igualitário apresentam-se como obstáculos à integração.

No domínio perspectivas futuras, como aspecto favorável à socialização, predomina o desejo de ascensão, característico de uma carreira altamente hierarquizada que, além da questão salarial, traz consigo o reconhecimento embutido nas patentes. Já a sensação de desmotivação e frustração pela demora nas promoções, contribui para desfavorecer o processo de socialização.

De modo geral, os resultados buscaram contribuir para a literatura que alinha a socialização organizacional às mulheres na Polícia Militar, profissão ainda caracterizada por muitos estereótipos masculinos, e isto possibilitou identificar como ocorre o processo de socialização organizacional das mulheres na polícia militar, o que retrata um caráter inovador para o estudo.

\section{Considerações finais}

Este artigo buscou compreender o processo de socialização organizacional das mulheres da Polícia Militar do Ceará. Foi possível constatar que esse processo é permeado tanto por aspectos que favorecem quanto por aspectos que dificultam a integração das mulheres na organização. Percebeu-se que polícia militar apresenta uma forte cultura organizacional, permeada por incontáveis aspectos simbólicos, que valorizam qualidades consideradas típicas do universo masculino, e que contribui para a manutenção da organização em meio às transformações que ocorrem no ambiente externo. Essa peculiaridade da instituição serviu como pano de fundo para que a compreensão do processo de socialização.

Verificou-se, no domínio treinamento, que o treinamento formal oferecido no início da carreira policial militar foi de suma importância para a socialização das policiais militares recém-ingressas. Mesmo após esse treinamento inicial de caráter intensivo, ficou evidenciada a relevância do treinamento informal. O aprendizado diário obtido por meio de observação, tentativa e ajuda dos colegas mais experientes mostrou-se bastante eficiente na aquisição de novas habilidades relacionadas ao trabalho, visto que ocorre em situações reais. Após a fase inicial, o treinamento informal mostrou-se mais relevante que o treinamento formal para o processo de socialização das policiais femininas na PMCE.

Em relação ao domínio compreensão, notou-se que o curso de formação contribui significativamente para o processo de socialização das policiais recém-ingressas, advindas do mundo civil, na cultura militar. As entrevistadas revelaram-se conhecedoras dos aspectos que envolvem a instituição Polícia Militar, tais como missão, valores e cultura. A cultura e os valores da Polícia Militar, por sua vez, mostraram-se influentes no dia a dia profissional das policiais, tendo sido internalizados por algumas delas, influenciando seu comportamento também no âmbito privado.

O domínio suporte dos colegas de trabalho revelou-se bastante influente no processo de socialização das policiais femininas da PMCE. As entrevistadas relataram a importância desse suporte para o trabalho na polícia, o qual necessita do apoio de uma equipe integrada. O suporte dos colegas é imprescindível em situações críticas do trabalho nas ruas, pois o apoio de um companheiro pode salvar a vida de outro. $\mathrm{O}$ suporte dos colegas foi associado, ainda, ao apoio emocional e moral, visto que, diante de algum problema, de natureza profissional ou pessoal, há uma mobilização dos colegas no sentido de oferecer ajuda para que aquela dificuldade seja contornada. 
No domínio das perspectivas futuras, notou-se que o fator que atraiu a maioria das entrevistadas para ingressar na Polícia Militar foi a estabilidade oferecida pelo emprego público. As expectativas de futuro das policiais convergiram para ascensão na carreira, havendo, contudo, um sentimento de frustração, provocado pela demora nas promoções. Este não atendimento de expectativas gera sentimentos negativos não só nas policiais femininas como também em toda a tropa. Entretanto, a corporação teve suas esperanças renovadas com a mudança de governo. Assim, algumas das policiais que projetavam ascensão, receberam sua promoção e continuam almejando postos mais altos.

Não foram encontradas grandes disparidades dentro de cada domínio de socialização. As divergências mais significativas ocorreram quando as entrevistadas com mais tempo de casa e as mais recentes relataram seu processo de adaptação à organização Polícia Militar. As policiais com mais tempo de instituição revelaram ter enfrentado mais dificuldades, enquanto as policiais com menos tempo de organização, consideraram que o processo se deu de forma mais fácil, sem grandes problemas. Essas divergências podem ser explicadas pelo fato de a organização e seus membros estarem mais adaptados à presença de mulheres em seus quadros, o que torna o processo de socialização mais orgânico hoje do que no passado.

Este artigo contribui para a literatura sobre socialização organizacional, especificamente sobre mulheres inseridas em ambientes de trabalho "masculinizados", notadamente marcados pela subordinação de gênero. O caso da Polícia Militar mostra-se relevante, visto que instituição é particularmente considerada masculina, seja pelo fato de ter seus quadros representados por homens; seja pela natureza do trabalho de polícia que, muitas vezes, requer uma postura mais agressiva; seja por se tratar de um meio militar, o qual é perpassado por muitas particularidades simbólicas. Em uma visão mais ampla, também contribui para identificar as transformações pelas quais algumas organizações tradicionais vêm passando para se adequar às novas posições que as mulheres têm ocupado no mercado de trabalho e na sociedade, além das peculiaridades desse processo de inserção.

Esta pesquisa apresenta limitações, já que a realização de um único estudo, com profissionais desta categoria específica, restringe a análise à visão deste grupo. Estudos futuros podem ampliar o conhecimento do assunto, replicando a metodologia aqui utilizada, com o intuito de investigar o processo de socialização de mulheres em outras organizações policiais. Também é válido analisar outras profissões comumente caracterizadas como masculinas. Pesquisas dessa natureza podem permitir comparar a socialização organizacional de mulheres nesses nichos profissionais.

\section{Referências}

ANDERSON, R. C.; KLOFSTAD, C. A.; MAYEW, W. J.; VENKATACHALAM, M. Vocal fry may undermine the success of young women in the labor market. PloSOne, v. 9, n. 5, p. e97506, 2014.

APARÍCIO, I. C. S.; MELO, K. S.; SILVA, E. P.; CALVOSA; M. V. D. Carreira feminina: quebrando paradigmas e alcançando sucesso. In: Simpósio de Excelência em Gestão e Tecnologia, 7, 2009, Rio de Janeiro, Anais... Rio de Janeiro: SEGe'T, 2009.

BARDIN, L. Análise de Conteúdo. Lisboa: Edições 70, 1977.

BAUER, T. N.; BODNER, T.; ERDOGAN, B.; TRUXILLO, D. M.; TUCKER, J. S.Newcomer adjustment during organizational socialization: a meta-analytic review of antecedents, outcomes, and methods. Journal of Applied Psychology, v. 92, n. 3, p. 707-721, 2007.

BERGER, P.; BERGER, B. Socialização: como ser um membro da sociedade. Sociologia e sociedade. Rio de Janeiro: LTC, 1978. 
BORGES, L. O; ALBUQUERQUE, F. J. B; Socialização organizacional. In: ZANELLI, J. C., BORGES-ANDRADE, J. E., BASTOS, A. V. B. (Orgs.). Psicologia, Organizações e Trabalho no Brasil. 1. ed., p. 331-356. Porto Alegre: Artmed, 2004.

BRASIL, L.; PEREIRA, A. N.; MACHADO, V. L. A inserção do gênero feminino na empresa vis-à-vis a participação feminina na população economicamente ativa: um estudo de caso da companhia energética do Paraná (COPEL). Gestão e Sociedade, v. 3, n. 5, p. 95-113, 2009.

CALAZANS, M. E. Mulheres no policiamento ostensivo e a perspectiva de uma segurança cidadã. São Paulo em perspectiva, v. 18, n. 1, p. 142-150, 2004.

CAPELLE, M. C. A.; SILVA, Á. L.; BOAS, L. H. D. B. V.; BRITO, M. J. Representações das relações de gênero no espaço organizacional público. Revista de Administração Pública, v. 36, n. 2, p. 253275, 2002.

CAPPELLE, M. C. A.; MELO, M. C. O. L. Mulheres policiais, relações de poder e de gênero na Polícia Militar de Minas Gerais. Revista de Administração Mackenzie, v. 11, n. 3, p. 72-99, 2010.

CARVALHO, V.; BORGES, L. O.; VIKAN, A. Socialização organizacional: estudo comparativo entre servidores públicos brasileiros e noruegueses. Revista Eletrônica de Administração, v. 18, n. 2, p. 339-371, 2012.

CARVALHO NETO, A. M.; TAMURE, B.; ANDRADE, J. Executivas: Carreira, maternidade, amores e preconceitos. RAE-eletrônica, v. 9, n. 1, 2010.

CHAO, G. T.; O'LEARY-KELLY, A. M.; WOLF, S.; KLEIN, H. J.; GARDNER, P. D. Organizational Socialization: Its content and consequences. Journal of Applied Psychology, v. 79, n. 5, p. 730-743, 1994.

COLLIS, J.; HUSSEY, R. Pesquisa em administração: um guia prático para alunos de graduação e pós-graduação. 2. ed. Porto Alegre, RS: Bookman, 2005.

DONADIO, M. La mujer en las instituciones armadas y policiales: resolución 1325 y operaciones de paz en América Latina. Buenos Aires: RESDAL -Red de Seguridad y Defensa de América Latina, 2009.

ELLIS, A. M.; BAUER, T. N. How do We get new entrants 'On 9 Board'? Organizational socialization, Psychological contracts, and realistic Job Previews. An Introduction to Work and Organizational Psychology: An International Perspective, p. 159-175, 2017.

ELLIS, ALLISON M.; NIFADKAR, S. S.; BAUER, T. N.; ERDOGAN, B. Newcomer adjustment: Examining the role of managers' perception of newcomer proactive behavior during organizational socialization. Journal of Applied Psychology, v. 102, n. 6, p. 993-1001, 2017.

FELDMAN, D. C. A contingency theory of socialization. Administrative science quarterly, p. 433452, 1976.

FERNANDES, K. R.; ZANELLI, J. C. O processo de construção e reconstrução das identidades dos indivíduos nas organizações. Revista de Administração Contemporânea, v. 10, n. 1, p. 55-72, 2006.

FERNANDO, W. D. A. A social constructionist perspective of gender stereotyping at work: a case of highly skilled women in Sri Lanka. Gender in Management: An International Journal, v. 27, n. 7, p. 463-481, 2012. 
IRAGARAY, H. A. R.; VERGARA, S. C. Mulheres no ambiente de trabalho: abrindo o pacote "gênero". ENCONTRO ANUAL DA ANPAD, Anais... São Paulo: ANPAD, 33, 2009.

KANAN, L. A. Poder e liderança de mulheres nas organizações de trabalho. Organizações \& Sociedade, v. 17, n. 53, p. 243-257, 2010.

MEYERSON, D.; FLETCHER, J. A modest manifesto for shattering the glass ceiling. Harvard Business Review. Boston: Harvard Business Press, 2000.

MORAES, E. L. A política de promoção da igualdade de gênero e a relação com o trabalho. In: Igualdade de gênero e raça no trabalho: avanços e desafios. Brasília: OIT, 2010.

MOURA, E. B. B. Além da Indústria Têxtil: o trabalho feminino em atividades masculinas. Revista Brasileira de História, v. 9, n. 18, p. 86-96, 1989.

MUNDIM, F. L. C.; TEODÓSIO, A. S. S. (des)caminhos e encruzilhadas das mulheres na outra economia: um estudo de caso no assentamento rural pastorinhas. Gestão e Sociedade, v. 5, n. 11, p. 104-120, 2011.

MUSEU DA PMCE. Policiamento feminino da PMCE. Disponível em:< http://museu.pm.ce.gov.br/historicos/especiaispoliciamentos.htm>. Acesso em: 22 jan. 2016.

MUSUMECI, L.; SOARES, B. M. Polícia e Gênero: participação e perfil das policiais femininas nas PMs brasileiras. Revista Gênero, v. 5, n. 1, p. 183-207, 2012.

PERROT, S.; BAUER, T. N.; ABONNEAU, D.; CAMPOY, E; ERDOGAN, B.; LIDEN, R. C. Organizational socialization tactics and newcomer adjustment: The moderating role of perceived organizational support. Group \& Organization Management, v. 39, n. 3, p. 247-273, 2014.

QUEIROZ, H. M. G. et al. Diversidade nas organizações: construindo um olhar sobre a evolução da mulher no contexto organizacional. In: ENCONTRO ANUAL DA ANPAD, 34., 2010, Rio de Janeiro. Anais... Rio de Janeiro: ANPAD, 2010.

RIBEIRO, A. N.; GARCIA, F. C. Relações de poder e gênero no alto comando da polícia militar de Minas Gerais: uma análise da percepção das mulheres policiais. Teoria e Prática em Administração, João Pessoa, v. 5, n. 1, p. 53-79, 2015.

RISK, C. N. Análise dos egressos de uma faculdade pública admitidos em programas de trainees: socialização antecipatória, choque de realidade e ingresso na organização. 2010. Dissertação (Mestrado em Administração de Organizações) - Faculdade de Administração, Economia e Contabilidade, Universidade de São Paulo, Ribeirão Preto, 2010.

ROSA; I. O. "Eu era o terceiro homem": um estudo de gênero com mulheres policiais civis e militares. 2012. Dissertação (Mestrado em Psicologia Social do Trabalho e das Organizações) Instituto de Psicologia, Universidade de Brasília, Brasília, 2012.

SILVA, A. H.; FOSSÁ, M. I. T. O processo de socialização organizacional como estratégia de integração indivíduo e organização. REUNA, v. 18, n. 4, p. 5-20, 2013.

SILVA, S. G. Preconceito e discriminação: as bases da violência contra a mulher. Psicologia: ciência e profissão, v. 30, n. 3, p. 556-571, 2010.

SILVEIRA, N. S. P. Entendendo a experiência de inclusão-exclusão de mulheres em cargos de gerência. In: ENCONTRO DA ANPAD, 33., São Paulo, 2009, São Paulo. Anais ... São Paulo: ANPAD, 2009. 
SOUZA, E. M. CORVINO, M. M. F.; LOPES, B. C. Uma análise dos estudos sobre o feminino e as mulheres na área de administração: a produção científica brasileira entre 2000 a 2010. Organizações \& Sociedade, v. 20, n. 67, p. 603-621, 2013.

TAORMINA, R. J. Organizational socialization: A multidomain, continuous process model.

International Journal of Selection and Assessment, v. 5, n. 1, p. 29-47, 1997.

TAORMINA, R. J. Interrelating leadership behaviors, organizational socialization, and organizational culture. Leadership \& Organization Development Journal, v. 29, n. 1, p. 85-102, 2008.

VAN MAANEN. Processando as pessoas: estratégias de socialização organizacional. In: FISCHER, R. M.; FEURY, M. T. L. Cultura e poder nas organizações. 2. ed. São Paulo: Atlas, 1996. 